\title{
Reply
}

\section{Reply to Rizzo et al.}

\author{
Arndt Vogel $^{\mathrm{a}} \quad$ Javier Sanchez Alvarez ${ }^{\mathrm{b}} \quad$ Monica Daigl ${ }^{\mathrm{b}} \quad$ Philippe Merle $^{\mathrm{c}}$ \\ ${ }^{a}$ Hannover Medical School, Hannover, Germany; ${ }^{b}$ F. Hoffmann-La Roche Ltd, Basel, Switzerland; ${ }^{c}$ Hepatology Unit, \\ Hôpital de La Croix-Rousse, Lyon, France
}

\section{Dear Editor,}

We thank Rizzo et al. for their comments regarding our systematic review and network meta-analysis (NMA) comparing systemic treatments for unresectable hepatocellular carcinoma [1].

We appreciate the comments made about risk of bias. However, we considered these limitations in our study and, after careful evaluation, still assessed the risk of bias as generally low as 7 of 9 studies had a low risk of bias for at least 4 of 7 domains. Considerations of heterogeneity are important and were assessed in the Source Data Analysis subsection and online supplementary Table 3 in our article. Random-effects models incorporated measures of heterogeneity in the analyses. In our network, betweentrial heterogeneity could not be assessed solely on the basis of the data in the network because of the very limited number of trials per pairwise comparison (a maximum of 7 trials with data could be considered, and there was a maximum of 2 trials comparing the same treatments) [2]; the Bayesian analyses borrowed information from previously published studies [3].

We agree with Rizzo et al. that adverse events and safety profiles are more difficult to compare using standard Bayesian NMA methods due to the reasons mentioned in the Discussion section.

Rizzo et al. suggest that Bayesian NMA may be linked with inflation of type I and II errors. However, inflation of type I error applies only in repeated testing without

karger@karger.com
www.karger.com/lic

Karger"
C 2021 The Author(s).

Published by S. Karger AG, Basel

This article is licensed under the Creative Commons Attribution 4.0 International License (CC BY) (http://www.karger.com/Services/ OpenAccessLicense). Usage, derivative works and distribution are permitted provided that proper credit is given to the author and the original publisher. considering a spending in the context of a living NMA with continuous updating [4]. This is not the case for our study [1]. Furthermore, the results of each meta-analysis indicate the current best evidence and need to stand on their own merit, as recommended by the Cochrane Expert Panel [5]. Finally, because NMAs generally analyze clinical trial data, statistical power to detect treatment differences can potentially be increased. In our case, uncertainty was relatively large due to the limited number of trials informing each pairwise comparison.

While we do believe that NMAs can be very informative to indirectly compare treatments based on available clinical trials, we also believe that clinical trials should remain the gold standard to evaluate new potential standards of care whenever clinically feasible.

\section{Acknowledgment}

Support for editorial assistance for this letter, furnished by Jeff Frimpter, MPH, of Health Interactions Inc., was provided by F. Hoffmann-La Roche Ltd.

\section{Statement of Ethics}

The authors have no ethical conflicts to disclose for this systematic literature review and meta-analysis.
Correspondence to:

Arndt Vogel, vogel.arndt@mh-hannover.de 


\section{Conflict of Interest Statement}

A.V. received honoraria, consulting fees, and speaker bureau fees from AstraZeneca, Cambridge, UK; Bayer, Leverkusen, Germany; Bristol-Myers Squibb, New York, NY, USA; BTG, London, UK; Eisai, Woodcliff Lake, NJ, USA; Lilly, Indianapolis, IN, USA; Incyte, Wilmington, DE, USA; Ipsen, Paris, France; Janssen, Beerse, Belgium; Merck, Kenilworth, NJ, USA; MSD, Kenilworth, NJ, USA; Novartis, Basel, Switzerland; Pierre Fabre, Paris, France; Roche, Basel, Switzerland; Sanofi, Paris, France; and Servier, Suresnes, France. J.S.A. and M.D. are employees and shareholders of F. Hoffmann-La Roche, Ltd. P.M. received consulting fees from Bayer, Ipsen, Lilly, Eisai, Roche, AstraZeneca, Bristol-Myers Squibb, and Roche; travel expenses from Bayer, Ipsen, Roche, and Bristol-Myers Squibb; and research funding (to institution) from Ipsen.

\section{Funding Sources}

This study was sponsored by F. Hoffmann-La Roche Ltd and Genentech Inc., South San Francisco, CA, USA, a member of the Roche Group. The study sponsor participated in the design, collection, analysis, and interpretation of data and in the drafting and critical review of the report. The authors had full access to all the data used in the analysis and shared responsibility for the decision to submit for publication.

\section{Author Contributions}

All authors participated in the writing and editing of the report and accept responsibility to submit for publication.

\section{References}

Reply to Rizzo et al.
1 Vogel A, Rimassa L, Sun HC, Abou-Alfa GK, El-Khoueiry A, Pinato DJ, et al. Comparative efficacy of atezolizumab plus bevacizumab and other treatment options for patients with unresectable hepatocellular carcinoma: a network meta-analysis. Liver Cancer. 2021;10: 240-8.

2 Higgins J, Thomas J, Chandler J, Cumpston M, Li T, Page M, et al., editors. Cochrane handbook for systematic reviews of interventions. Version 6.1. Cochrane Collaboration; 2021. Available from: https://training.cochrane.org/handbook Accessed 2021 Feb 28.

3 Turner RM, Jackson D, Wei Y, Thompson SG, Higgins JP. Predictive distributions for between-study heterogeneity and simple methods for their application in Bayesian meta-analysis. Stat Med. 2015;34(6):984-98.

4 Nikolakopoulou A, Mavridis D, Furukawa TA, Cipriani A, Tricco AC, Straus SE, et al. Living network meta-analysis compared with pairwise meta-analysis in comparative effectiveness research: empirical study. BMJ. 2018; 360:k585.

5 Cochrane Scientific Committee. Should Cochrane apply error-adjustment methods when conducting repeated meta-analyses? 2021. Available from: https://methods.cochrane.org/sites/default/files/public/uploads/tsa_expert_panel_guidance_and_recommendation_final.pdf Accessed 2021 Feb 28. 